\title{
[Accepted version]
}

\section{'Cold intimacies' in parents' negotiations of work-family practices and parental leave?}

\section{Katherine Twamley}

\begin{abstract}
This article aims to assess the contention that a 'feminist' ideology is associated with a 'cooling' of intimacy in heterosexual relationships, as argued by scholars such as Arlie Hochschild and Eva Illouz. According to this thesis, such an ideology, 'abducted' by a commercial spirit, encourages women to disengage from warm intimate bonds with others and to prioritize their own personal fulfillment and parity in care and housework. Drawing on two qualitative empirical studies exploring couple's intimate lives and their feminist and egalitarian preferences and practices in leave, care and housework, this article examines in detail the basis of this thesis, and its effectiveness in explaining the lived experiences of parent couples' negotiations of this terrain. The data were collected through focus group discussions with parents not sharing leave and a detailed ethnography with couples sharing leave. The comparison shows that, far from observing a clear dichotomy between 'cold' feminists and 'warm' traditional couples, both sets of parents present a more complex picture of 'warm' and 'cold' relations. The analysis enables a critical appreciation of sociological theorising about gender equality and intimacy, contributing to sociological debates around individualism, feminism and family life.
\end{abstract}

Keywords: Intimacy; Feminism; 'cold intimacy'; parental leave; gender equality 


\section{Introduction}

This article assesses the contention that a 'feminist' ideology is associated with a 'cooling' of intimacy, as argued by scholars such as Arlie Hochschild and Eva Illouz. According to this thesis, feminism 'abducted' by a commercial spirit, encourages women to disengage from warm intimate bonds and to prioritize their own personal fulfillment and parity in care and housework. Theses of a 'cooling of intimacy' have received broad attention and support within sociological scholarship, but little empirical evidence has sought to examine whether and how they are borne out in individuals' experiences of personal life. Drawing on two empirical studies focused on couples' intimate lives, as well as their feminist and egalitarian preferences and practices in leave, care and housework, this article will examine in detail the basis of the cultural cooling thesis, and its effectiveness in explaining the lived experiences of heterosexual parent couples. The analysis enables a critical appreciation of sociological theorising about gender equality and intimacy, contributing to sociological debates around individualism, feminism and family life.

\section{Cooling of intimacy}

In her influential book on the commercialization of intimacy, Hochshild (2003) compared feminist and 'traditional' self-help books directed at women in the 1970s and $80 \mathrm{~s}$, concluding that feminist books are 'cold' since they encourage readers to prioritize personal freedom and autonomy over strong emotional attachments. Contrasting the 'Total woman' written by Marabel Morgan, with 'The Cinderella Complex' by Collette Dowling, Hochschild describes how 'warm' Morgan's writing is - she writes like a friend about a friend, describing happy anecdotes of her relationship with her husband. Despite Morgan's subscription to a patriarchal authoritarian relationship between husband and wife, Hochschild argues that overall Morgan's message is for women to move 'forward and in, not backward and out of relationships' (2003:19). In contrast, the 'feminist books' reaffirm the ideal of equality, but undermine that of emotionally rich social bonds. They are 'cold' in that they encourage an ethic of autonomy and reliance on the self. These examples, Hochschild argues, demonstrate an 'abduction' of feminism that serves to legitimate a commercial spirit of intimate life.

Hochschild's analysis has been taken up enthusiastically by a range of scholars ${ }^{i}$ but her analysis somewhat overstates the case. While it is true that the 'modern' advice books appear to encourage an autonomous independent self, the 'traditional' books arguably fail to advocate loving relationships between husband and wife by encouraging what appears to be a one-sided warm engagement. In an excerpt she discusses from Morgan's book, for instance, Morgan relates how she 'braced herself' for her husband's 'icy tones' when she inadvertently arranged meal plans without his prior consent (Hochschild 2003:18). Women may well be conjoined upon to invest in their relationships with their husbands, but this is a unidirectional warmth, placing the responsibility for 'warm' personal life firmly on women.

Arguing along similar lines to Hochshild, Eva Illouz $(2007 ; 2008)$ and Frank Furedi (2012) make the case that the rise of feminism and popular psychology (as well as other factors such as new technologies of choice) have led to the rationalisation and thus cooling of intimacy. They argue that norms of symmetry in intimate relations encourage men and women to monitor their relationships with one another, and to 
evaluate one another's participation in domestic chores. Like Hochschild, Illouz critiques the 'feminist' focus on autonomy and self-reliance over intimate relations with others (2008: 138), but goes further in delineating the 'market logic' which concerns for symmetry bring:

Feminism creates techniques of control that enable the self to monitor power differentials with the ultimate aim of creating dialogical equal relationships. ... scientific language, feminism, and Internet technology all contribute to disembed the erotic bond through the formal rules provided by scientific knowledge systems, technology, and contractual proceduralism. (2008: 184)

Further, Illouz (2012) argues that increased rationalisation and individualism in modern society more generally leads to a greater range of choices for women, but also a cooling of intimacy since romantic decisions are now based on bargaining and reason. As discussed by Carter (2018) this analysis leaves little space for consideration of structural constraints.

Like Illouz, Furedi also critiques the 'contractual relations' of egalitarian couples. While writing a response to a Norwegian study which found higher divorce rates amongst couples that shared housework compared to those that did not, he asserts that the findings are not surprising since egalitarian marriages are more likely to be regarded from a utilitarian and transactional perspective:

Intimacy, and the kind of emotions associated with love and trust, cannot withstand the corrosive consequence of the introduction of a contractual and transactional ethos. Pragmatism and calculation are important for running a well organised office but they are likely to render formal what works best as an intimate and informal relationship. In effect they empty intimate relations of meaning. (Furedi, 2012)

The argument that a more egalitarian relationship is necessarily 'contractual' and 'transactional' is not based on any empirical evidence, other than the cited association between equality and divorce. In fact, other studies have suggested the opposite association - that is, that increased levels of egalitarianism between couples may increase relationship stability (e.g. Schober, 2013). Historically, and across cultures, marital and other intimate familial relations have been based on contractual and traditional systems of reciprocity and/or understandings of give and take, without a necessary absence of intimacy (Jamieson, 2012). To claim an incompatibility of rationality with love relies on a narrow understanding of emotion, ignoring empirical evidence demonstrating that these are not incommensurate (e.g. Twamley, 2014).

Arguments of a 'cooling of intimacy' straddle two bodies of sociological literature that of the relation between individualization and intimate life, and between feminism and family life, in particular the feminist 'backlash' literature. There is substantial overlap in these literatures, but they come together most precisely in theories of 'cooling intimacy'. In the individualization literature, scholars such as Bauman (2001; 2003) and Beck and Beck-Gernsheim (1992; 1995) argue that traditional forms of personal relationships are being undermined by values of autonomy, and the marketdriven logic of consumption and individual attainment. For Beck and BeckGernsheim (1995) the breakdown of traditional roles of the sexes, as seen by the increased numbers of women entering paid employment, has been a key factor in the 
fragility of contemporary relationships. While according to Bauman (2003), romantic relationships have been commodified into transactions, with individuals constantly seeking out something or someone 'better'. For Giddens $(1991,1992)$, on the other hand, the dissolution of traditional family and gender roles is suggested to be an opportunity for the 'pure relationship' to flourish - an intense couple connection noted for its gender equality - but which is also 'confluent', existing solely while the couple are satisfied by it (1991:6). Giddens views same-sex couples as at the fore of these transformations - an issue largely left aside by cooling intimacy theorists. Overall, 'individualisation' and the breakdown of traditional gender roles are posited as destabilizing intimate couple connections as individuals focus more on the self.

While it is true that increased numbers of women have entered paid employment, there is little evidence of a true transformation (UNDP, 2016). Furthermore, amongst certain social groups - namely working class women - rates of participation in paid employment have long been high. Arguments of such a radical transformation rely on a narrow (Western) middle class perspective. Moreover, the emphasis on individualisation as a key factor in changes in personal life has been persistently challenged (Jamieson, 1998; Smart, 2007). Nevertheless, the claims of selfish individualism and relationship breakdown remain in circulation in both academic and popular discourse.

In the relation between feminism and family life, the focus is less on adult relations, and moves more squarely to the impact on children and women as mothers. Here feminism is charged with being detrimental to children's concerns. For example, Barrie Thorne (1987:104) observed in the late 1980s that women's emancipation is often framed as 'necessarily gained at the expense of children'. In a close examination of the sociology of the feminist backlash, Ann Oakley (1997) demonstrates how backlash authors rely on selective and simplified readings of feminist texts. The large body of feminist literature which celebrates 'feminine' attributes, or branches of socialist feminism are ignored. For Oakley, the backlash stems from a reaction to second-wave feminism that identified families as a key source of gender inequality, thus defending family becomes a key way to contest feminism (1997: 35). More contemporary forms of this argument can be found in 'fathers' rights' literature, such as in Stephen Baskerville's book 'Taken into custody: The War against Fathers, Marriage and the Family', where he charges feminism with the breakdown of family life and men's isolation from their children. As uncovered by Crowley's (2008) indepth research with father's rights groups in the US, such groups stress 'a more childcentered focus' (p. 36), but their rhetoric and practices are deeply antifeminist.

Arguably 'cooling intimacy' theorists also draw on selective readings of 'feminism'. Hochschild and Illouz fail to define the kind of feminism they are referring to in their writing, while Furedi focuses on 'egalitarian couples'. Such imprecision strengthens the association of their arguments with the feminist backlash literature. But feminism is not a monolithic movement and there is a danger in lumping all feminisms together, even if qualified as 'abducted' (is the 'feminist cause' abducted?). The proffered association with individualism suggests they are referring to a strand of liberal feminism. Andrea Doucet writes that this form of feminism is most prevalent in the literature on gendered divisions of domestic labour, reflecting a particular concern with parity in work and care roles. These studies, she argues, over-emphasise what 
women lose by their greater care role - 'status, financial rewards and work opportunities' - with less attention to what they may gain - 'personal growth, relationships and connection with their children' (1998:53-4). This scholarship is informed by an ontology that 'accepts the traditional liberal conception of human nature and the characteristic liberal values of individual dignity, equality, autonomy and self-fulfilment' (Jaggar, 1983: 39, in Doucet 1998). Illouz, for example, states that, 'Women have been enjoined both by feminism and by therapy to clarify their values and preferences [...] all with the goal of asserting an autonomous and selfreliant self' (2008: 137-138). This can be contrasted with a maternal feminist perspective, which has sought to emphasise the strengths, and benefits of participation in care and relations with others (e.g. Ruddick, 1995).

The liberal feminist perspective has been critiqued as neglecting 'connection with children' (Doucet, 1998:54). This is reflected in the scant attention to children in the above discussions of a cooling of intimacy. The absence of children is curious, though reflective of a wider trend within feminism and scholarship on personal life which tends to foreground adult relations (Ribbens McCarthy \& Edwards 2002; Twamley, Rosen, \& Mayall, 2017). But if women are being encouraged to disengage from 'warm' relations by 'feminism', as Hochschild argues, or to seek parity in care work, as Illouz and Furedi write, then this may impact on their relations with children too. The inattention to relations with children also serves to conflate housework with care work, which as scores of feminists shown, are not understood in the same way by women.

In this article, I examine the proposed relation between (liberal) feminism and intimacy in research with heterosexual parents in the UK, focused on their leave decisions and experiences after the birth of a child. I examine how participants conceptualize 'fairness' and 'equality', and whether and how they attempt to achieve parity in care and work roles. Moving beyond the sole focus on 'warmth' within couples, I also consider the implications for relations between parents and their children. I argue that, far from observing a clear dichotomy between 'cold' feminists and 'warm' traditional couples, the findings demonstrate a more complex picture of 'warm' and 'cold' elements.

\section{The research}

I draw on two research projects, both undertaken a short time after the introduction of a new and extended leave access for fathers in the UK, Additional Paternity Leave (APL). Understanding parents' views, experiences and decision-making around this leave was a key aim. APL was introduced in 2011 to promote a more equal division of childcare and paid work between parents (BIS, 2013). The policy allowed mothers to transfer their 52-week maternity leave to their partners, from 20 weeks after the birth or adoption of a child. The leave is in addition to the two weeks of Paternity Leave available to men (usually taken at the time of birth, with the mother). ${ }^{\text {ii }}$ Uptake of APL was very low -around $1.4 \%$ of eligible men between 2012 and 2013. ${ }^{\text {iii }}$

In the first study, I undertook focus group discussions with parents of preschool children, none of whom had taken APL. In the second study, I conducted in-depth interviews with ten parents (five couples) who were taking APL. In this paper, I contrast the narratives of those that shared leave via APL (in the second study) with 
those that did not (in the first). While not all couples who take APL will do so in an effort to realize egalitarian gender roles, I explore to what extent they do, and how such decisions impact on or are perceived to impact on their intimate relationships.

Comparing focus group discussions with data from interviews presents methodological challenges. Focus groups are perhaps more likely than interviews to elicit socially approved behaviour and rhetoric - the wider 'cultural' stories (Richardson, 1990). This may lead to less nuanced narratives than are possible in individual interviews. Individual and couple data offer more in-depth analysis for each participant, and may be considered a safer space to relate views and experiences outside of the perceived 'norm'. Participants may find it easier to relate in individual interviews unflattering experiences with their partners.

\section{Theoretical background}

The analysis treats gender as a relational concept (Connell, 2002), and motherhood and fatherhood as contingent and interrelated (Mac an Ghaill \& Haywood, 2007). The kinds of roles that parents take are worked out together and within a socially constructed and moralized context which frames understandings of 'mother' and 'father'. As Doucet writes in relation to fathers' take up of parental leave:

The decisions for fathers to take parental leave are negotiated relationally with their partners and workplace bosses and peers within a larger relational network that can include other parents, peers, and kin. (2017:20)

Previous research around leave practices and parenting practices tends to assume an individualised self, who makes a conscious 'choice' about personal behaviour. Where relations are taken into account, these are often conceptualised as two (or more) autonomous and even rival individuals who defend their separate positions. This concept of agency neglects the role of habitual (unplanned) action (Duncan, 2015) and its deeply emotional aspects (Holmes, 2004; Pham, 2013). In this study I draw on feminist scholarship (Benhabib, 1986; Gilligan, 1982) that emphasizes the relationality of persons, and the negotiation of decisions and practices. 'Negotiation' is understood widely, and not necessarily confined to explicit 'discussion'. It is clear that some positions can be taken as 'non-negotiable'; parents may, for example, simply follow traditional patterns without much explicit thought or discussion (Duncan, Edwards, Reynolds, \& Alldred, 2003). For the purposes of this study, I classify this is as 'negotiation', in that when a mother's role is, for example, seen as necessarily that of the main carer, the father's is correspondingly seen as that of breadwinner - both parents 'negotiate', or react to, perceived appropriate gendered models of parenting. This focus on relationality brings personal relationships into a central frame of analysis, without losing sight of the social context in which negotiations take place.

\section{Methods}

The focus group discussions were held in 2015 in London with parents of children under three. The aim was to elicit discussion on norms and values around parenting and leave. Participants were asked to discuss four questions: What is the purpose of maternity leave? What is the purpose of fathers' leave? What factors do people take into account when considering whether and how much leave to take? What would be your ideal leave provision? Participants were recruited via nursery schools and 
parent-toddler groups, and the discussions were held in community halls, with one undertaken at the researcher's university. Attendees were as follows: Focus Group 1 (FG1), six female attendees; FG2 four females; FG3 five females and two males; and FG4 one female and two males. Only one couple participated (in FG3). None of the participants had taken APL, but all had given birth since the introduction of the policy. The majority of participants were white, and approximately half were UKborn and half from other European countries. All were in heterosexual relationships. Further demographic information was not collected, though conversations during group discussions indicated that many held professional jobs.

The second study, also conducted in 2015 in London, included ten parents (five couples) where the father was taking APL. The parents were recruited via online parent forums, antenatal classes, personal connections and a parenting blog. These participants were all white, heterosexual, first-time parents, in their 30s or above, and had a university education. Individual income levels varied across the sample, from less than $£ 20,000$ per annum, to between $£ 61,000$ and $£ 100,000$ per annum. In all couples the man and woman earned similar amounts or the woman earned more. ${ }^{\text {iv }}$ All men took a minimum of three months APL. ${ }^{v}$ Participants were interviewed first with their partner present and then separately. They were asked about their pregnancy, birth, early leave-taking experiences, motivations to take APL, and their experiences in the first year after the birth of their child.

Group discussions and interviews were digitally recorded and transcribed. The transcriptions were uploaded to NVIVO and analysed using methods of constructivist grounded theory (Charmaz, 2006). Ethical guidelines from the British Sociological Association were followed. All participants are given a pseudonym to protect their anonymity.

\section{Findings}

\section{Parents not sharing leave - warm intimates?}

Amongst those that had not shared leave, it seemed that APL had never been broached as a potential option. Many of the participants were not aware of the availability of APL, nor knew of other families that had taken it. Within the focus group (FG) discussions I asked participants to consider whether they might have taken APL if they had known about it, or whether they might consider doing so in the future. On the whole, participants were not keen. The desirability of men taking a more active role in fathering was questioned, along with the potential of leave to shape more egalitarian relations between women and men. Participants emphasized women's mothering roles, with a more limited, primarily breadwinning role, for men.

Due to the transferral design of the leave policy in the UK, in order for fathers to take APL, mothers must first relinquish a portion of their maternity leave. This emerged as a major barrier to APL, as women reported not wanting to reduce their leave duration. Women described immensely enjoying leave and a desire to continue being engaged in their children's lives as primary carers. In FG1, for example, women spent considerable time complaining what they felt was a UK policy agenda to get mothers into paid employment: 
Ann: I want to stay at home with him [son], but you know, stop [unclear], and start helping people to stay at home somehow or make it possible for people to look after their own children - I'd love to.

Barbara: At 3 years old I think, they have those free nursery hours, well why don't you pay mums to stay at home with their children for 15 hours a week? vi $^{\text {in }}$

Ann: Exactly!

(FG1, All female group)

Another participant in FG3 (mixed sex group) reported feeling like a 'feminist traitor' because she enjoyed her leave with her child, she said she can 'actually fathom the notion of not going back [to her job], which is kind of heresy in my world for women to say that.' There is then a perceived social pressure to return to work and to 'want' to return to work, indicating a 'liberal feminist' context, in which feminism is associated with an emphasis on women's role in paid employment over time with their children.

Railing against this perceived context, in the two all female focus groups, mothers argued that fathers taking leave was potentially counterproductive to their own parenting and intimacy goals. There was a fear amongst these mothers that fathers would take 'their' leave and have an excellent time with the child, without any advantages for the mother:

Ciara: But it will usually be the case [if fathers take leave] that you get home and you still got to do all the stuff that hasn't been done, having been at work all day so it's slightly different. It's not like, like we were just talking about having a child minder where it's just amazing, or em you know if you had a nanny I would imagine you come home to a nice tidy house...em it's a bit different to that.

(FG2, All female group)

These women felt that fathers taking leave was likely to result in more housework for women and less caring between themselves and their children. There emerged a perception that intimate care relations with their children were potentially being sacrificed in the pursuit of more symmetrical work roles and balanced leave uptake.

Even if women would 'love it if somebody would also do that invisible work' (that is taking responsibility and completing housework), they do not think their partners taking leave would be the answer, rather they fear that it would lead to a 'second shift' (Hochschild, 2003) without the attendant benefits of being the primary carer. These accounts demonstrate a lack of trust in men's ability or willingness to undertake housework. Laughter and merriment were likely to accompany the anecdotes of ineffectual male partners. Some participants adhered to fairly stereotypical gendered ideas of men and women, but even those that critiqued such notions did not go so far as to suggest any structural or inherent inequality in their familial situation.

In addition to women reporting their preferred primary care role, a concern for partners' feelings and preferences around parenting and employment was also proffered as important in shaping leave practices. Often this was articulated as women's preference to be at home, and men's to be at work. Here female participants talk about men likely being 'bored' on leave: 
Ann: I think [husband] would be bored out of his brain looking after a baby for three months.

Gill: And what about you?

Ann: Oh I was, yeah. I'm quite - well maybe it depends on how much you care about your career or the job you're doing. He seems to really like his...

Denise: I think when you're a mum you tend to be - you tend to meet other mums and you do go and hang out and you have that kind of social connection [...] I think men just - they do find that harder, is my sense. Then like one dad hanging out with loads of women and how did they feel and-yeah, so I think...

(FG1, All female group)

Meanwhile male participants tended to focus on how their partners wanted to take maternity leave:

'[my wife] really wanted to stay [at home], she really enjoyed it and I thought it was really good [...] what's good for the kid, what's good for you, that's good for the family.'

(FG4, mixed sex group)

Some men expressed a desire to be 'able' to take more leave - for example in a context where it was better remunerated or less stigmatized - but that in the current context, their partners' take up of leave was prioritized. Such gendered ideas and practices around leave were then extended to a question I posed on 'ideal parental leave': the preference was to offer fathers a slightly extended paternity leave to facilitate fathers' leave at the same time as mothers, so that fathers could support mothers' caring role by taking care of housework.

\section{APL takers - cold feminists?}

Participants in the second study cited gender equality at a national and personal level as their main motivation to take APL. Two women (Evie and Kylie) explicitly mentioned feminism as being a key motivating factor, while all women described a concern for symmetry in housework and care work as their reasons to share leave. One couple reported using an excel sheet downloaded from an equal parenting website to monitor divisions of house and care work. Concerns for equal parenting were far more vociferously articulated by women than men. Three women reported intentionally withholding care in order to 'compel' their partners into a more equal split of parenting. For example, one woman reported how she deliberately ignored a notification from the health visitor, explaining that if she told her partner, he would never learn to think about such things. Such instances were defended by participants with statistics of how much more care work women do than men, and that such tactics were needed to prevent gendered patterns emerging in their own families.

A concern for symmetry could also be seen to over-ride at times relational concerns for a partner. For example, in the following conversation Evie considers under what circumstances she would be satisfied if her husband John chose not to take APL after a second (planned) child:

I guess if he found that the three months out of work was really detrimental to his ... working process or whatever, and he was really struggling to get back into where he was and had forgotten important things and that stuff, maybe I would have been more sympathetic to that. But then I think that's the same for 
women as well, so I don't know. I'm not sure I would have been entirely sympathetic under any circumstances. [laughs] Evie (Healthcare Worker, 9 months leave)

This extract reveals how Evie's desire for equal parenting takes her a step away from sympathizing with John's imagined predicament in his job, as she compares his experience to those of women more generally.

Nonetheless, care work was also defined as a privilege from which men have traditionally been excluded. Couples emphasized their desire to share emotional connection with their newborn child as a right for fathers, something that other fathers miss out on, and an experience that can increase bonding and intimacy overall in the family. This was a key motivation to share leave from men in particular, as Arthur explains:

I think is that if you spend that time in that first year, like, with the child doing those practical things, that you develop a kind of $a$. bond and sort of just the habit of being involved in the child's life very early on, which then will carry on throughout its life, I think? Arthur (Librarian, 3 months leave)

Three of the couples also said that taking APL had increased mutual empathy, since they both understood the difficulties of full-time parent care. They cited seeing other couples who frequently argued due to lack of symmetry in roles and wanting to avoid this by setting up more equal roles.

Even parents' negotiations about more mundane aspects of housework seemed to contradict Furedi's notion of 'contractual interactions'. Couples talked about taking on household and other work when their partner appeared to be particularly tired or stressed. If we return to Evie again, here she explains:

If the other one is having a difficult time and [we] might take up the slack somewhere else with housework or with [daughter] or with. whatever it is. So it's quite a movable dynamic in terms of who's doing what, jobs wise. We've probably got some jobs that normally one of us does and the other one does, but that moves with time and with different situations.

Care is involved in the decisions around housework and care work, even when 'fairness' and symmetry are held as important values.

Couple deliberations around leave reveal similar concerns. Across the sample of APL couples, women's proclaimed feminist and egalitarian goals were downplayed in the couples' narratives as influences over the couple's ultimate decision to share leave. For instance, when first asked about why she and her partner used APL, Kylie told me it was down to her 'capital F Feminism'. Later, however, she told me that she 'would not have expected a partner to necessarily take time out of the workplace'. When I queried her on this apparent incongruence, she told me:

I wouldn't have expected a partner to necessarily be prepared to take time out of the workplace. So, but then I would have had difficulty because I would have wanted to - I would have felt more torn because I wanted to go back to work at six months [...] So yeah, then I think I probably would have . not necessarily You can't force someone to stay at home with a baby and neither do you want to do that because if the person doesn't really want to be at home, then it's not going to be a good experience for the baby or that person. Kylie (Accountant, 6 


\section{months leave)}

This quote demonstrates how women negotiate a balance between their egalitarian and intimate caring goals. Kylie states that despite being a 'capital F Feminist', she would not 'expect' a man to take leave from work; she then quickly moves on to 'force' as being inimical to care. One must 'care' (as in deem important) in order to care for. Kylie extrapolates that forcing a man to take care of a child will not result in good care for the child. We can also infer that it would not have been a demonstration of 'care' for her partner. The decision to take APL and to negotiate it with her husband brings an element of interpersonal risk (Lupton, 1999) - not only is she (and her husband) taking a risk by participating in a new form of UK leave policy, but she risks upsetting relations with him if negotiated with 'force'. She says it would not be a good experience for 'that person', referring to her husband, though she reports that she would have lost out herself by potentially having to take longer leave from her career than she wanted to. In this and other parts of her interviews, she demonstrates her care for her partner and child, even when her previously stated 'main motivation' to share leave was to establish equal parenting.

\section{Discussion}

In the first study using focus groups, gender egalitarian goals, interpreted as symmetry in paid and unpaid work and equal opportunities in the workplace, are portrayed as futile and as of secondary importance to care for a child. Women expressed a strong desire to spend time with their children, and argued that their male partners were happier in their paid employment then they would be at home. Overall, they wanted men at home for a short family leave, to increase family bonds and support the maternal care role. Like some of the mothers in Duncan et al's study, these mothers appear to value mothering as 'an alternative to the mores of modern capitalist society, including a rejection of paid work as a moral duty' (2003: 316). They could be interpreted as embracing a 'maternal feminist' perspective, given the talk about the perceived devaluation of care work; they could also be taken as rejecting the more 'liberal' feminist approach critiqued by the cooling of intimacy scholars.

These mothers also reported wanting more involvement from their partners in housework and less discrimination in the workplace; they were simply not convinced that parental leave would improve their situation. They did not monitor their partners' contributions to care and housework in a bid to equalize it, but noted the inequality, and professed an inability to change it, or an overall contentment with the status quo. Women in focus groups laughed together over the impossibilities of bringing men into housework, indicating a normative recognition of men's failure to take up the less pleasant aspects of 'home' work. Research does suggest that where men become more involved in care, they tend to take on the more 'fun' aspects (Craig, 2006). The narratives in the group discussions may indicate a preference to accept what feels impossible to change.

Perhaps, as Beck and Beck-Gernshein (1995) proposed, these women are focusing on the more 'solid' or permanent relations with their children as an antidote to insecure intimate adult relationships. They report excluding men from care roles in a bid to avoid their own exclusion. Involvement in childcare affords parents a close and intimate relationship with their children (Gabb, 2008), to which fathers are potentially losing out. These mothers reported making complicated adjudications and exceptions 
- inhibiting men's equal access to care and accepting as inevitable men's inability to pull their weight around the house - in order to maintain their intimate ties with children, and possibly with men (by avoiding confrontation). Meanwhile, women (and men) posit that there are more barriers to men's take-up of leave - that he may be more penalized at work for taking time out, for example. Men report self-excluding from parental leave, prioritizing mothers' access to leave and her caring role (see McKay \& Doucet, 2010 for similar findings in Canada). The policy context - a transfer of maternity leave from the mother to the father - clearly contributes, since women are obliged to give up part of their leave to facilitate father's access (O'Brien $\&$ Twamley, 2017). This normalizes leave as primarily for women, and necessitates a reduction in maternity leave if men are to take it. In contexts where leave is an individual right, such as in Nordic countries, men's take-up of leave is normalized and even expected (O’Brien \& Wall, 2017).

For participants in the second study, symmetry in care and housework - that is similar divisions of similar tasks - was a primary concern in their relationships, particularly for the women. These couples described various means through which they monitored and divided care work and housework. As such, these couples conform to the supposedly 'transactional' character of relationships criticized by Illouz (2007) and Furedi (2012), who argued that such 'rational' approaches to measuring housework remove spontaneity and warmth from couple relationships. There was little evidence, however, of disengagement from personal relationships, as observed by Hochschild in 'feminist' advice books. While there were instances where a concern for symmetry in roles could be seen to distance women from empathizing with their partner, the predominant theme was that of participants seeking to show love and care throughout deliberations over care and housework practices. These findings echo those of Holmes's research with 'long distance' couples. She argued that women in such relationships struggled to gain recognition as individuals, while also 'resisting the transference of principles of rationality exercised in the work- place to the intimate realm' (2004:181). More broadly, one may argue that most individuals struggle with reconciling personal goals with their commitments to others (Ball, Vincent, Kemp, \& Pietikaien, 2004). As Lynch argues, this is the reality of human existence that is lived within 'affective relational realities' (2007:555).

Arguably the couples who express a concern for symmetry in roles, ultimately bring men into care and increase bonds between fathers and their children. Large-scale quantitative studies show that men's uptake of leave promotes their involvement in childcare (and housework) (e.g. Schober, 2014), with qualitative research demonstrating men's positive bonding experiences when on leave alone with their children (O'Brien \& Wall, 2017). Extended leave alone can enable fathers to sympathize with mothers' stress and the practices of combining work and care (ibid). Couples in this study reported increased intimate bonds which they attributed to their shared experiences of the transition to parenthood, as well as greater empathy towards one another. Bringing men into care is a key aim of maternal feminists, who argue that such practices could form the basis of radical change, leading to a 'world organized by the values of caring labour' (Ruddick, 1995:135). Participants did not articulate or delineate themselves as 'maternal feminists', nor liberal feminists; individuals and their actions are unlikely to fall neatly into definitions of feminism from academic scholarship. 
The careful deliberations over parental leave expressed by participants in the second study also highlight the gendered moral context in which parents negotiate practices. By apparently 'giving up' some of their leave to their partners, the mothers were exposing themselves to criticism that they were placing themselves and their own wishes before the interests of their child and partner. For example, when asked about the reactions of others to their decision to take up APL, Kylie reports that her motherin-law disapproves:

There was a comment about kind of "investing in your children is the best investment you can make". I think that comment was probably em, was probably when I had positioned going back early as partly for my own wellbeing em, in terms of the amount of time that I would ideally like to take off em, and then still be able to pursue my own career aspirations. Kylie (34yrs, Accountant, 6 months leave)

For Kylie, her mother in-law's disapproval stems from the fact that she presented APL as 'partly for my own well-being'. No such rebukes were directed at men, indicating that processes of 'individualisation' are unevenly experienced (Holmes 2004). As numerous previous studies have identified, women are typically expected to show priority to the care of others, over and above themselves. Feminist attempts to destabilize such gendered notions of care responsibilities have been met with fierce resistance, with feminists long being caricatured as selfish (Tyler, 2007) or a killjoy (Ahmed, 2010). Discourses of a 'selfish feminist' work against women through guilt, constraining their ability to challenge a lack of equality in both private and public spheres. Hochschild, Illouz and Furedi's arguments draw on what is now a very familiar discourse about the corrosive effect of modern life on personal relationships, particularly the effect of individualism on women's commitments to family (Bellah, Madsen, Sullivan, Swidler, \& Tipton, 1985). The evidence presented in this article suggests that such discourses of 'feminism' do not play out so neatly in people's lives.

\section{Conclusions}

This article presents and contrasts data from two different studies exploring heterosexual parents' decision-making around parental leave in the UK. While the studies used different data collection methods, both elicited narratives on parents' deliberations and negotiations around gendered care and work practices. In contrast to theorizations of the relationship between a liberal feminist ethic and 'cold intimacy', the comparison demonstrates a more complex story. There is no clear dichotomy between 'cold feminists' and 'warm traditionalists', in both cases negotiations around leave and parenting practices involve emotional labour and care work. In the first study, this meant a reaffirmation of gendered practices around leave and parenting, despite expressed preferences for more equality in the workplace and in housework (from the women). Like the 'traditional' advice books described by Hochschild, familial harmony - that is 'warm relations' with others - is emphasized above gender symmetry. However, when considering adult-child relations, we can see that mothers who do not seek symmetry, at least in this study, place a strong emphasis on their relations with their children, but in doing so, may also exclude fathers from a closer relationship with their children. On the other hand, men's reported reluctance to undertake housework (not so much care work) contributes to their partners' reluctance to share more equally the care role. Men and women are both 'individualised' and family oriented in their negotiations, despite following a more traditional pattern of parenting practices. 
In the second study, 'feminist' mothers and fathers reported valuing and experiencing improved relations with their children and with one another, due to sharing leave. While symmetry in housework and care work was reported as a strong priority for the women, this did not entail a rejection of warmth; participants described exceptions and limits to their preference for symmetry. These data demonstrate that a search for symmetry in intimate relationships does not necessarily result in cold contractual transactions. On the contrary, women may continue to work with their partners to try to carve out a more equal but 'warm' intimate relationship.

The analysis presented here throws new light on popular theorisations of 'cultural cooling' by bringing in empirical data that unsettle its assumptions. The cooling of intimacy thesis conflates 'feminism' with 'liberal feminism', while participants in fact rarely follow any such delineations. I have also shown that a preference for symmetry is not necessarily associated with 'cold' rationality and, by bringing children into the frame, that in fact increased warm family relations may be the contrary result. Overall, the cooling intimacy argument relies on an idea of modern society as overwhelmingly individualist, despite repeated previous research to the contrary, to which this analysis further contributes.

The conclusions drawn from these studies must, however, be tempered by their limitations, drawing as they do on a relatively small sample of mostly white UK middle class professionals. Such individuals are potentially more likely to be exposed to, and to benefit from, discourses of liberal feminism. Further, same-sex couples may practice feminisms in very different ways. Future research should aim to explore these intersections with participants from more diverse backgrounds.

Acknowledgements: Many thanks to Professor Ann Oakley for comments on drafts of this article, and to the anonymous reviewers for their feedback and suggestions. A very special thank you to those who participated in the research. The research was funded by The British Academy.

\section{References}

Ahmed, S. (2010). Feminist Killjoys (And Other Willful Subjects). The Scholar and Feminist Online Journal, 8(3).

Ball, S., Vincent, C., Kemp, C., \& Pietikaien, S. (2004). Middle class fractions, childcare and the "relational" and "normative" aspects of class practices. The Sociological Review, 52(2), 478-502.

Bauman, Z. (2001). The Individualized Society. Cambridge: Polity.

Bauman, Z. (2003). Liquid Love. Cambridge: Polity Press.

Beck, U. (1992). Risk Society: Towards a new Modernity. London: Sage.

Beck, U., \& Beck-Gernsheim, E. (1995). The Normal Chaos of Love. Cambridge: Polity Press.

Bellah, R., Madsen, R., Sullivan, W., Swidler, A., \& Tipton, S. (1985). Habits of the Heart: Individualism and commitment in American life. . Berkeley: University of California Press. 
Benhabib, S. (1986). Critique, Norm and Utopia. New York: Columbia University Press.

BIS. (2013). Modern Workplaces: Consultation on the administration of Shared Parental Leave and Pay - government response: Department for Business Innovation.

Carter, J. (2018) Women (not) troubling the family: Exploring women's narratives of gendered family practices. Journal of Family Issues. ISSN 1552-5481 [In Press]

Charmaz, K. (2006). Constructing Grounded Theory. A Practical Guide Through Qualitative Analysis. London: Sage.

Connell, R. (2002). Gender. Cambridge: Polity Press.

Craig, L. (2006). Does Father Care Mean Fathers Share? A Comparison of How Mothers and Fathers in Intact Families Spend Time with Children. Gender \& Society, 20, 259-281.

Crowley, J.E., (2008). Defiant Dads: Fathers' Rights Activists in America. Ithaca, NY: Cornell University Press

Doucet, A. (1998). Interpreting Mother-Work: Linking Ontology, Theory, Methodology and Personal Biography. Canadian Woman Studies, 18, 52-58.

Doucet, A. (2017). The Ethics of Care and the Radical Potential of Fathers 'Home Alone on Leave': Care as Practice, Relational Ontology, and Social Justice. In M. O'Brien \& K. Wall (Eds.), Fathers on leave alone and gender equality: An international comparative perspective. London: Springer.

Duncan, S. (2015). Women's agency in living apart together: constraint, strategy and vulnerability. The Sociological Review, 63(3).

Duncan, S., Edwards, R., Reynolds, T., \& Alldred, P. (2003). Motherhood, paid work and partnering: values and theories. Work, Employment \& Society, 17(2), 309330 .

Faludi, S. (1991). Backlash: The undeclared war against women. London: Vintage.

Furedi, F. (2012). Why the 'couples where women do more housework stay together' study isn't shocking. The Independent, http://www.independent.co.uk/voices/comment/why-the-couples-where-womendo-more-housework-stay-together-study-isnt-shocking-8192069.html

Gabb, J. (2008). Researching intimacy in families. Basingstoke [England] ; New York: Palgrave Macmillan.

Giddens, A. (1991). Modernity and self-identity. Self and society in the late modern age. Cambridge: Polity Press.

Giddens, A. (1992). The Transformation of Intimacy: Sexuality, Love, and Eroticism in Modern Societies. Stanford, California: Stanford University Press.

Gilligan, C. (1982). In a different voice: Psychological theory and women's development. Cambridge MA: Harvard University Press.

Hochschild, A. R. (2003). The Managed Heart: the Commercialization of Human Feeling. Berkeley, CA: University of California Press.

Holmes, M. (2004). The precariousness of choice in the new sentimental order. Current Sociology, 52(4), 251-257.

Illouz, E. (2008). Saving the Modern Soul: Therapy, Emotions, and the Culture of Self-Help. London: University of California Press.

Illouz, E. (2012) Why love hurts: A sociological explanation. Cambridge: Polity Press.

Jaggar, A. M. (1983). Feminist Politics and Human Nature. Totowa, NJ: Rowman and Alenheld. 
Jamieson, L. (1998). Intimacy: Personal relationships in modern societies Cambridge: Polity Press.

Jamieson, L. (2012). Intimacy as a Concept: Explaining Social Change in the Context of Globalisation or Another Form of Ethnocentrism. Sociological Research Online, 16.

Lupton, D. (1999). Risk. London: Routledge.

Lynch, K. (2007). Love labour as a distinct and non-commodifiable form of care labour. Sociological Review, 55(3).

Mac an Ghaill, M., \& Haywood, C. (20007). Gender, Culture and Society: Contemporary Femininities and Masculinities. London: Palgrave Macmillan.

McKay, L., \& Doucet, A. (2010). "Without taking away her leave": A Canadian case study of couples' decisions on fathers' use of paid leave. Fathering, 8(3), 300320.

O'Brien, M., \& Twamley, K. (2017). Fathers taking leave alone in the UK - a gift exchange between mother and father? . In M. O'Brien \& K. Wall (Eds.), Comparative perspectives on Work-Life Balance and Gender Equality: Fathers on leave alone. London: Springer.

O'Brien, M., \& Wall, K. (2017). Comparative Perspectives on Work-Life Balance and Gender Equality: Fathers on leave alone. London: Springer.

Oakley, A. (1997). A Brief History of Gender. In A. Oakley \& J. Mitchell (Eds.), Who's Afraid of Feminism? Seeing through the Backlash. New York: The New Press.

Pham, Q. (2013). Enduring bonds: politics and life outside freedom as autonomy. Alternatives: Global, Local, Political, 38(1), 29-48.

Ribbens McCarthy, J., \& Edwards R. (2002). The individual in public and private: the significance of mothers and children. In A. Carling, S. Duncan \& R. Edwards (Eds.), Analysing Families: Morality and Rationality in Policy and Practice. London: Routledge.

Richardson, L. (1990). Narrative and Sociology. Journal of Contemporary Ethnography, 19, 116-135.

Ruddick, S. (1995). Maternal Thinking: Toward a Politics of Peace. Boston: Beacon Press.

Schober, P. (2013). Gender Equality and Outsourcing of Domestic Work, Childbearing, and Relationship Stability Among British Couples. Journal of Family Issues, 34(1), 25-52.

Schober, P. S. (2014). Parental Leave and Domestic Work of Mothers and Fathers: A Longitudinal Study of Two Reforms in West Germany. Journal of Social Policy, 43(2), 351-372.

Smart, C. (2007). Personal Life: New Directions In Sociological Thinking. Cambridge:: Polity.

Thorne, B. (1987). Re-visioning women and social change: Where are the children? Gender and Society, 1(1), 85-109.

Twamley, K. (2014). Love, Marriage and Intimacy among Gujarati Indians: A Suitable Match Basingstoke: Palgrave Macmillan.

Twamley, K., Rosen, R., \& Mayall, B. (2017). The (im)possibilities of dialogue across feminism and childhood scholarship and activism. Children's Geographies, 15(2), 249-255.

Tyler, I. (2007). The Selfish Feminist. Australian Feminist Studies, 22(53), 173-190.

UNDP. (2016). Human Development Report 2016. NY: United Nations Development Programme. 



been cited 1,386 times, and the article of this chapter in Theory Culture and Society, has been cited 193 times, according to google scholar (last checked on the $1^{\text {st }}$ February 2018).

ii In April 2016, Shared Parental Leave (SPL) replaced APL, allowing mothers to transfer their maternity leave to their partners from two weeks after the birth or adoption of a child, as well as facilitating parents to take leave at the same time.

iii http://www.publications.parliament.uk/pa/cm201314/cmhansrd/cm140403/text/140403w0001.htm

${ }^{\text {iv }}$ See O'Brien and Twamley (2017) for a discussion on the importance of salary parity in couple's decisions around leave

${ }^{\mathrm{v}}$ More detail on these participants can be found in O'Brien and Twamley (2017).

${ }^{\mathrm{vi}}$ UK childcare provision includes 15 free childcare hours during term time for all children from three years.
} 